\title{
Expression of hypoxia-inducible factor (HIF) $-1 \alpha$ and vascular endothelial growth factor (VEGF)-D as outcome predictors in resected esophageal squamous cell carcinoma
}

\author{
Ching Tzao ${ }^{\mathrm{a}, *, 1}$, Shih-Chun Lee ${ }^{\mathrm{a}, 1}$, Ho-Jui Tung ${ }^{\mathrm{c}}$, Han-Shui Hsu ${ }^{\mathrm{b}}$, Wen-Hu Hsu ${ }^{\mathrm{b}}$, Guang-Huan Sun ${ }^{\mathrm{d}}$, \\ Cheng-Ping $\mathrm{Yu}^{\mathrm{e}}$, Jong-Shiaw $\mathrm{Jin}^{\mathrm{e}}$ and Yeung-Leung Cheng ${ }^{\mathrm{a}}$ \\ ${ }^{a}$ Division of Thoracic Surgery, Tri-Service General Hospital, National Defense Medical Center, Taipei, Taiwan \\ ${ }^{\mathrm{b}}$ Division of Thoracic Surgery, Veterans General Hospital, Taipei, Taiwan \\ ${ }^{\mathrm{c}}$ Department of Humanity and Social Studies, National Defense Medical Center, Taipei, Taiwan \\ ${ }^{\mathrm{d}}$ Department of Surgery, Tri-Service General Hospital, National Defense Medical Center, Taipei, Taiwan \\ ${ }^{\mathrm{e}}$ Department of Pathology, Tri-Service General Hospital, National Defense Medical Center, Taipei, Taiwan
}

\begin{abstract}
Hypoxia-inducible factor (HIF)- $1 \alpha$ and vascular endothelial growth factor (VEGF) are important angiogenic factors in human cancers. Relative to VEGF-C, prognostic significance of VEGF-D expression and its association with HIF- $1 \alpha$ expression remain elusive in esophageal squamous cell cancer (ESCC). We studied expression of HIF-1 $\alpha$ and VEGF-D using immunohistochemistry in 85 resected ESCC specimens and correlated results with patients' clinicopathologic parameters and survival. Association between expression of HIF-1 $\alpha$ and VEGF-D was investigated using a concordance analysis. High expression of HIF- $1 \alpha$ and VEGF-D was observed in $52(61.2 \%)$ and $56(65.9 \%)$ patients, respectively. HIF-1 $\alpha$ expression correlated well with tumor stage $(P=0.041)$, whereas VEGF-D expression correlated with tumor stage $(P=0.027)$ and N status $(P=0.019)$. Groups of high HIF-1 $\alpha$ and VEGF-D showed worse survivals than those of low expression $(P=0.002$ and 0.001 , respectively). Multivariate analysis supported expression of HIF-1 $\alpha$ and VEGF-D as significant survival predictors $(P=0.044$ and 0.035 , respectively). A concordance rate of $69.5 \%$ was observed between expression of HIF-1 $\alpha$ and VEGF-D. In conclusion, protein expression of HIF-1 $\alpha$ and VEGF-D are independent prognostic predictors. An association between expression of HIF-1 $\alpha$ and VEGF-D suggests that these two angiogenic factors are essential in progression of ESCC.
\end{abstract}

Keywords: Hypoxia-inducible Factor (HIF)-1 $\alpha$, vascular endothelial growth factor (VEGF)-D, esophageal squamous cell carcinoma, prognosis, survival

\section{Introduction}

Angiogenesis is essential for tumor growth and its spread, including invasion and metastasis [8]. This

\footnotetext{
${ }^{1}$ These authors contributed equally to this work.

*Corresponding author: Ching Tzao, M.D., Ph.D., Division of Thoracic Surgery, Tri-Service General Hospital, National Defense Medical Center, 325, Section 2, Cheng Gong Road, Nei Hu, Taipei, Taiwan 114. Tel.: +8862 87927167; Fax: +8862 26347961; E-mail: tzao@yahoo.com.
}

process relies on production of a number of angiogenic factors by tumor and surrounding host cells [9]. A key regulator in this process is the transcription factor hypoxia-inducible factor-1 (HIF-1), which targets several genes related to cell proliferation, angiogenesis or invasion in response to a hypoxic microenvironment within the tumor [18,21,34].

HIF-1 is a heterodimeric basic helix-loop-helix protein composed of HIF- $1 \alpha$ and HIF- $1 \beta$ subunits [24]. Under normoxic conditions, the HIF- $1 \alpha$ subunit is subjected to ubiquitination and proteosomal degradation; 
whereas in hypoxia, its degradation is inhibited, and its expression increases rapidly [42]. Tumors derived from cells lacking HIF- $1 \alpha$ or HIF- $1 \beta$ show significantly reduced vascularization and often reduced growth rates compared with parental cells [4,32].

A key angiogenic factor whose gene expression is regulated by HIF-1 is the vascular endothelial growth factor (VEGF) [21]. Under hypoxic conditions within the tumor cells, HIF- $1 \alpha$ binds to a DNA recognition sequence in the promoter of target genes, including the VEGF gene [30]. Thus, under hypoxic conditions, VEGF transcription is up-regulated by HIF, and additionally hypoxia promotes the stabilization of VEGF mRNA by proteins that bind to sequences in the 3 ' untranslated region (3' UTR) of the mRNA [6].

VEGF is a family of the platelet-derived growth factor composed of 6 VEGF members including VEGF-A, VEGF-B, VEGF-C, VEGF-D, VEGF-E, and placenta growth factor (PIGF) [41]. The prognostic significance of VEGF expression has been reported in gastric, colon, breast, bladder and esophageal carcinomas, as well as in other malignancies $[7,16,17,31]$. Notably, previous studies for gastrointestinal malignancies have focused on expression of VEGF-C in relation to lymph node metastasis and survival, including gastric, esophageal, and colorectal carcinomas [2,10,22]. It remains controversial whether VEGF-D promotes angiogenesis and lymphangiogenesis like VEGF-C in human cancers $[26,29,37]$. In view of lack of correlative study of VEGF-D expression with clinical outcome in patients with esophageal squamous cell carcinoma (ESCC), this study aimed to clarify prognostic significance of expression of VEGF-D and HIF- $1 \alpha$ in the same series, and to investigate whether there is an association between expression of HIF-1 $\alpha$ and VEGF-D in resected ESCC.

\section{Research design and methods}

\subsection{Study population and tumor samples}

Archival paraffin-embedded tissue blocks were obtained retrospectively of primary tumor specimens from 85 patients who underwent esophagectomy from January 1997 to December 2001. These were serial patients who had a complete resection of the tumor and availability of sufficient follow-up data with an exclusion of in-hospital mortality. Patients included in this study did not receive preoperative chemotherapy or radiotherapy. Waiver of patient consent was granted by the Institutional Review Board, which allowed us to get access to patients' medical records and to obtain tissue samples and pertinent follow-up data. From review of medical records, clinical information was collected and TNM status was recorded based upon the American Joint Committee on Cancer (AJCC) staging system [12] for esophageal cancer. Survival and followup data were obtained from the Institutional Cancer Registry.

\subsection{Analysis of protein expression by immunohistochemistry (IHC)}

Paraffin blocks of tumors were cut into $5 \mu \mathrm{m}$ slices and then processed using standard deparaffinization and rehydration techniques. After antigen retrieval using microwave heating, all tissue sections on slides were immunostained following instructions from the antibody suppliers. A monoclonal anti-HIF- $1 \alpha$ antibody clone H1alpha67 (1:200; Novus Biologicals, Inc., Littleton, CO, USA) was used to detect HIF-1 $\alpha$ protein and monoclonal antibody clone 78923.11 against human VEGF-D (1:100; R\&D Systems, Minneapolis, MN, USA) was used to detect VEGF-D, respectively. The binding of primary antibody was visualized using a detection system (DAKO LSAB Kit K675; DakoCytomation California Inc., Carpinteria, California, USA). The normal staining patterns for HIF- $1 \alpha$ are nuclear and/or cytoplasmic, whereas that for VEGF$\mathrm{D}$ is cytoplasmic. Tumor cells that exhibited an absence of staining in the presence of surrounding nonneoplastic cells with cytoplasmic or nuclear staining were considered to have an abnormal pattern. Staining results were examined by two board-certified pathologists masked to patients' clinical information. Another reading by a third observer was needed to reach a consensus when there was a significant discrepancy between initial readings. The percentage of the tumor cells that exhibited a positive immunoreactivity was determined at x 200 magnification using a light microscope (Olympus BX51, Olympus America Inc.). To be in consensus with most studies of expression HIF$1 \alpha$ and VEGF in tumors by immunohistochemistry, we used scoring systems to distinguish low from high expression of HIF-1 $\alpha[1,19]$ and VEGF-D $[20,36]$ as previously described respectively. Briefly, both the percentage of positive cells and the intensity of the reaction were taken into account; 0 , no staining; $1,<1 \%$ positive cells; $2,1-10 \%$ positive cells with slight to moderate reaction; $3,10-50 \%$ positive cells with moderate to high reaction and $4,>50 \%$ positive cells with 


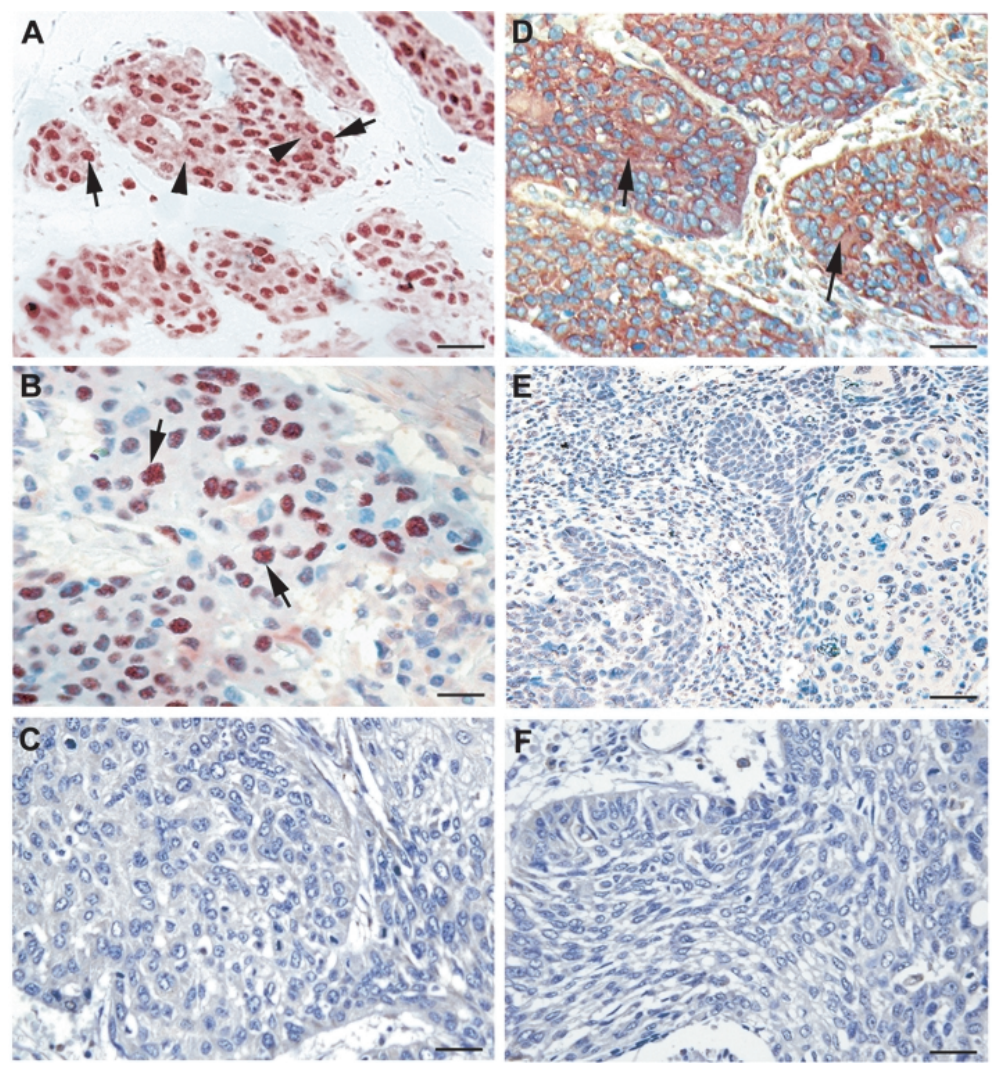

Fig. 1. Representative results of immunostaining for HIF-1 $\alpha$ (panels A-C) and VEGF-D (panels D-F) in resected specimens of esophageal squamous cell carcinoma. A. Positive HIF- $1 \alpha$ immunoreactivity was detected in nuclei (arrows) and cytoplasm (arrowheads) of tumor cells. B. Positive HIF- $1 \alpha$ immunoreactivity was detected only in nuclei of tumor cells. D. Positive immunoreactivity for VEGF-D was detected in the cytoplasm of tumor cells (arrows). E. Tumor cells stained negatively (arrows) for VEGF-D. C and F. Negative controls for immunostaining of HIF-1 $\alpha$ and VEGF-D stained negatively for all cells. Bars: A, C, D and F = 50 $\mu \mathrm{m} ; \mathrm{B}=40 \mu \mathrm{m} ; \mathrm{E}=100 \mu \mathrm{m}$.

moderate to high reaction. Staining scored as 0,1 , and 2 was considered as low expression, whereas the rest were considered as high expression. Mouse isotypematched $\mathrm{IgG} 2 \mathrm{~b}$ and $\mathrm{IgG}_{1}$ served as negative controls for HIF- $1 \alpha$ and VEGF-D antibody, respectively.

\subsection{Statistical analysis}

The Pearson $\chi^{2}$ or Fisher exact test as appropriate was used to compare expression of HIF- $1 \alpha$ and VEGFD protein with different clinicopathologic variables of the patients, including age, sex, tumor stage, and TNM category. The Kaplan-Meier method [14] was used to estimate the probability of survival as a function of time and median survival following esophagectomy. The log-rank test was used to assess the significance of difference between pairs of survival probabilities [39]. Multivariate analysis for survival was performed using the Cox proportional hazards models. Statistical analysis was performed using the SPSS software package, version 13.0 (SPSS Inc, Chicago, IL). A $P$ value less than 0.05 was considered statistically significant.

\section{Results}

\subsection{Protein expression of HIF-1 $\alpha$ and VEGF-D in relation to patients' clinicopathologic variables}

Representative immunohistochemistry results for protein expression of HIF- $1 \alpha$ and VEGF-D are shown in Fig. 1. The comparisons of protein expression of HIF-1 $\alpha$ and VEGF-D in relation to patients' clinicopathologic variables were summarized in Table 1. High expression of HIF- $1 \alpha$ and VEGF-D was observed in $52(61.2 \%)$ and $56(65.9 \%)$ patients, respectively. Expression of HIF- $1 \alpha$ correlated positively with tumor stage only ( $P=0.041)$, whereas expression of VEGFD showed significant positive correlation with tumor stage $(P=0.027)$ and $\mathrm{N}$ (nodal metastasis) $(P=$ 0.019). 
Table 1

Comparison between protein expression of HIF-1 $\alpha$ and VEGF-D, with clinicopathologic features for patients undergoing esophagectomy for squamous cell carcinoma of the esophagus

\begin{tabular}{|c|c|c|c|c|c|}
\hline \multirow[b]{2}{*}{ Characteristics } & \multirow[b]{2}{*}{ Patients } & \multicolumn{2}{|c|}{ HIF-1 $\alpha$ expression } & \multicolumn{2}{|c|}{ VEGF-D expression } \\
\hline & & High & Low $(\%)$ & High & Low $(\%)$ \\
\hline Overall & 85 & $52(61.2 \%)$ & $33(38.8 \%)$ & $56(65.9 \%)$ & $29(34.1 \%)$ \\
\hline \multicolumn{6}{|l|}{ Age } \\
\hline$\leqslant 70$ & 60 & 36 & 24 & 37 & 23 \\
\hline$>70$ & 25 & 16 & 9 & 19 & 6 \\
\hline \multicolumn{6}{|l|}{ Sex } \\
\hline M & 80 & 47 & 33 & 52 & 28 \\
\hline $\mathrm{F}$ & 5 & 5 & 0 & 4 & 1 \\
\hline \multicolumn{6}{|l|}{ Staging } \\
\hline $\mathrm{I}+\mathrm{II}$ & 48 & 25 & $23^{\mathrm{a}}$ & 27 & $21^{\mathrm{b}}$ \\
\hline III+IV & 37 & 27 & 10 & 29 & 8 \\
\hline TNM & & & & & \\
\hline $\mathrm{T} 1+2$ & 30 & 16 & 14 & 17 & 13 \\
\hline $\mathrm{T} 3+4$ & 55 & 36 & 19 & 39 & 16 \\
\hline No & 44 & 23 & 21 & 24 & $20^{\mathrm{c}}$ \\
\hline N1 & 41 & 29 & 12 & 32 & 9 \\
\hline M0 & 68 & 39 & 29 & 44 & 24 \\
\hline M1 & 17 & 13 & 4 & 12 & 5 \\
\hline
\end{tabular}

${ }^{\mathrm{a}, \mathrm{b}} P=0.041$ and 0.027 between stage $\mathrm{I}+\mathrm{II}$ and $\mathrm{III}+\mathrm{IV}$, respectively; ${ }^{\mathrm{c}} P=0.019$ between $\mathrm{N} 0$ and $\mathrm{N} 1$.

TNM: T, tumor invasion; N, regional lymph nodes; M, distant sties (metastases).

Table 2

Univariate Kaplan-Meier analysis for clinicopathologic variables and expression of HIF- $1 \alpha$ and VEGF-D

\begin{tabular}{|c|c|c|c|c|}
\hline Variables & Categories & $\mathrm{N}$ & $\begin{array}{l}\text { Survival time (months) } \\
\text { Median } \pm \text { SE (95\% C.I.) }\end{array}$ & $P$ value \\
\hline \multirow[t]{2}{*}{ Age (years) } & $\leqslant 70$ & 55 & $19.0 \pm 8.5(2.4-35.6)$ & \\
\hline & $>70$ & 30 & $18.0 \pm 6.2(5.9-30.1)$ & 0.675 \\
\hline \multirow[t]{2}{*}{ Sex } & Male & 80 & $19.0 \pm 5.0(9.1-28.8)$ & 0.222 \\
\hline & Female & 5 & $15.0 \pm 3.3(8.5-21.4)$ & \\
\hline \multirow[t]{4}{*}{ Tumor status $(\mathrm{T})$} & $\mathrm{T} 1$ & 7 & $29.0 \pm 20.9(0.0-70.1)$ & $0.032^{*}$ \\
\hline & $\mathrm{T} 2$ & 23 & $29.0 \pm 7.2(14.9-43.1)$ & \\
\hline & $\mathrm{T} 3$ & 48 & $15.0 \pm 6.9(1.4-28.6)$ & \\
\hline & $\mathrm{T} 4$ & 7 & $9.0 \pm 2.6(3.9-14.1)$ & \\
\hline \multirow[t]{2}{*}{ Nodal status (N) } & No & 44 & $29.0 \pm 0.9(27.1-30.9)$ & $<0.001^{*}$ \\
\hline & $\mathrm{N} 1$ & 41 & $15.0 \pm 3.9(7.4-22.7)$ & \\
\hline \multirow[t]{2}{*}{ Metastasis (M) } & M0 & 68 & $22.0 \pm 5.7(10.9-33.1)$ & $0.007^{*}$ \\
\hline & M1 & 17 & $10.0 \pm 3.4(3.3-16.6)$ & \\
\hline \multirow[t]{4}{*}{ Stage } & $\mathrm{I}$ & 5 & $30.0 \pm 0.4(29.1-30.9 .2)$ & $<0.001^{*}$ \\
\hline & II & 43 & $29.0 \pm 2.6(23.9-34.1)$ & \\
\hline & III & 22 & $10.0 \pm 0.9(8.2-11.8)$ & \\
\hline & IV & 15 & $6.0 \pm 2.9(0.3-11.7)$ & \\
\hline \multirow[t]{2}{*}{$\mathrm{HIF}-1 \alpha$} & Low & 33 & $30.0 \pm 1.1(27.8-32.2)$ & $0.002 *$ \\
\hline & High & 52 & $12.0 \pm 2.4(7.3-16.7)$ & \\
\hline \multirow[t]{2}{*}{ VEGF-D } & Low & 29 & $33.0 \pm 3.6(25.9-40.0)$ & $0.001^{*}$ \\
\hline & High & 56 & $12.0 \pm 2.3(7.4-16.6)$ & \\
\hline
\end{tabular}

${ }^{*}$ Difference is considered significant when $P<0.05$.

3.2. Survival analysis in relation to clinicopathologic variables including protein expression of HIF-1 $\alpha$ and VEGF-D

Univariate Kaplan-Meier analysis for clinicopathologic variables and expression of HIF- $1 \alpha$ and VEGF-
D was performed to determine survival predictor(s) and the results were summarized in Table 2. Among all variables analyzed, the groups of high expression of HIF- $1 \alpha$ and VEGF-D showed worse survivals than those of low expression $(P=0.002)$ and $(P=0.001)$, respectively (Fig. 2). Median survival durations in 
A

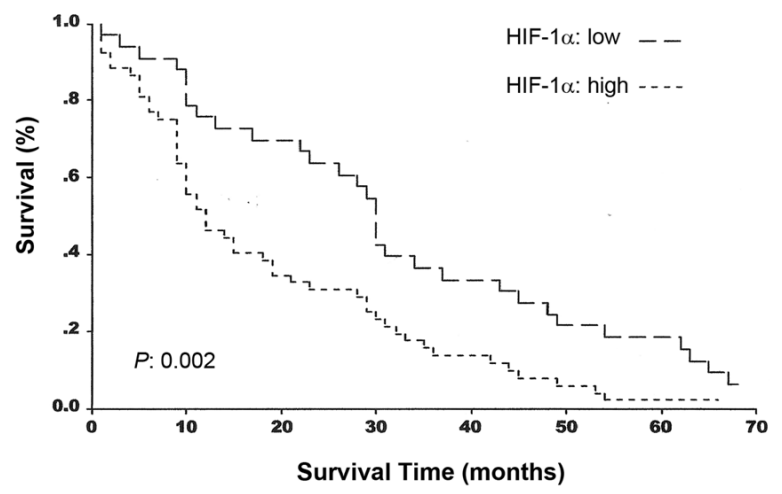

B

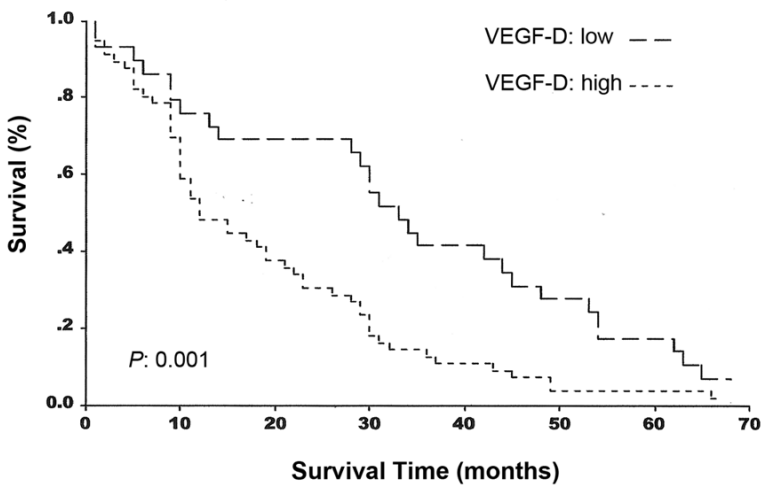

Fig. 2. Kaplan-Meier survival curve with log-rank test for 85 patients after resection for esophageal squamous cell carcinoma. Comparison of survival between patients with low and high expression of HIF- $1 \alpha$ protein and VEGF-D is shown in (A) and (B), respectively. Ninety five percent of confidence intervals (C.I.) for median survival in groups of low and high expression of HIF-1 $\alpha$ were 27.8-32.2 and 7.3-16.7, and in low and high VEGF-D groups, were 25.9-40.0 and 7.4-16.6, respectively.

months were $30.0 \pm 1.1$ and $12.0 \pm 2.4(\mathrm{SE})$ for patients with low and high expression of HIF-1 $\alpha$, and $33.0 \pm 3.6$ and $12.0 \pm 2.3$ for patients with low and high VEGF-D expression, respectively. Multivariate analysis for prediction of survival showed that tumor stage, expression of HIF- $1 \alpha$ and VEGF-D were independent survival predictors with a $P=0.019,0.044$ and 0.035 , respectively (Table 3 ).

\subsection{Correlation of protein expression of HIF-1 $\alpha$ with protein expression of VEGF-D}

Results of high HIF-1 $\alpha$ /VEGF-D and low HIF$1 \alpha /$ VEGF-D expressions were considered concordant. A concordance rate of $69.5 \%$ was observed between protein expression of HIF- $1 \alpha$ and VEGF-D $(P=$ 0.002) (Table 4).

\section{Discussion}

Previous studies on tumor angiogenesis have suggested an important role of HIF-1 as an inducer for angiogenic factors in hypoxic tumor microenvironment $[8,9,18,34]$. Among genes whose expression is regulated by HIF-1, VEGF is well-documented as a key angiogenic factor [21]. Correlation of expression of these two factors with clinical outcome has been widely investigated in a variety of human cancers including esophageal cancer $[16,17,22]$. Most of these studies on esophageal cancer have focused on expression of VEGF-C [17,22]. In view of lack of investigation concerning VEGF-D expression and association study for
Table 3

Multivariate analysis using a Cox proportional hazards model for variables including patients' clinicopathologic features and expression of HIF- $1 \alpha$ and VEGF-D

\begin{tabular}{lccl}
\hline Variable & HR & $95 \%$ CI & $P$ \\
\hline Age & 1.014 & $0.992-1.037$ & 0.214 \\
Sex & 0.729 & $0.275-1.938$ & 0.527 \\
Stage & 3.884 & $1.244-12.125$ & $0.019^{*}$ \\
T status & 0.793 & $0.537-1.170$ & 0.242 \\
N status & 1.272 & $0.474-3.413$ & 0.632 \\
M status & 1.158 & $0.570-2.350$ & 0.685 \\
HIF-1 $\alpha$ & 1.768 & $1.053-2.970$ & $0.044^{*}$ \\
VEGF-D & 1.738 & $1.035-2.920$ & $0.035^{*}$ \\
\hline
\end{tabular}

* Difference is considered significant when $P<0.05$.

Table 4

Concordance analysis between protein expression of HIF- $1 \alpha$ and VEGF-D in resected esophageal squamous cell carcinoma

\begin{tabular}{lcc}
\hline \multirow{2}{*}{ VEGF-D } & \multicolumn{2}{c}{ HIF-1 $\alpha$} \\
\cline { 2 - 3 } & High & Low \\
\hline High & $41(48.3 \%)^{*}$ & $11(12.9 \%)^{\dagger}$ \\
Low & $15(17.6 \%)^{\dagger}$ & $18(21.2 \%)^{*}$ \\
Concordant vs discordant & $59(69.5 \%)^{*}$ & $26(30.5 \%)^{\dagger}$ \\
\hline
\end{tabular}

Data were presented as actual numbers and percentages of cases in a total of 85 patients. ${ }^{*}$ Concordant: high HIF- $1 \alpha /$ VEGF-D and low HIF-1 $\alpha$ /VEGF-D expressions. ${ }^{\dagger}$ Discordant: high HIF- $1 \alpha /$ low VEGF-D and low HIF- $1 \alpha$ /high VEGF-D expressions. $P=0.002$ for correlation between protein expression of HIF-1 $\alpha$ and VEGF-D.

expression of HIF- $1 \alpha$ and VEGF-D in esophageal squamous cell carcinoma, we designed this study to investigate prognostic significance of expression of VEGF-D and HIF- $1 \alpha$ and the relationship between expressions of these two factors in a cohort of 85 resected ESCC.

Expression of HIF- $1 \alpha$ is enhanced by genetic alterations in tumor suppressor genes (von HippelLindau/VHL, p53, PTEN) and oncogenes (v-src, 
HER2neu, H-ras) and by the induction of several growth factors (insulin-like growth factor (IGF)-1 and IGF-2, basic fibroblast growth factor (bFGF), and epidermal growth factor (EGF) $[16,21]$. HIF- $1 \alpha$ activates transcription of VEGF through a direct binding HIF$1 \alpha$ binding site $[6,13]$. Inhibition of HIF- $1 \alpha$ results in down-regulation of VEGF and increased apoptosis of cancer cells $[23,44]$, indicating that HIF- $1 \alpha$ may serve as a potential target for cancer therapy while supporting its role as a key factor in tumor angiogenesis and tumor progression. HIF- $1 \alpha$ is absent in most normal tissues and its IHC staining patterns vary depending on different tissue types [45]. Consistent with staining pattern for HIF- $1 \alpha$ in ESCC [16], our results of HIF- $1 \alpha$ immunostaining also showed nuclear and/or cytoplasmic immunoreactivity in tumor cells.

Recent studies have shown that HIF-1 $\alpha$ expression correlates with VEGF expression and high expression of these two factors are generally considered as poor prognostic predictors in a various human cancers including esophageal cancer $[1,3,16]$. Kimura and associates reported a $39 \%$ of high expression of HIF- $1 \alpha$ in 32 out of their 82 ESCC tumor specimens and concluded that higher expression of HIF-1 $\alpha$ correlated positively with vascular invasion and microvessel density within the tumor but not tumor stage, individual TNM factors or survival for the entire patient cohort. In contrast, our results showed a higher rate of high HIF- $1 \alpha$ expression, 52 in 85 (61.2\%), of resected tumor specimens. Unlike their results, the expression of HIF- $1 \alpha$ correlated positively with tumor stage and inversely with patients' survival in our study. Discrepancies from these two studies may arise from different populations studied; for instance, different ethnic groups or their inclusion of patients with preoperative induction therapy. One may speculate that pre-operative induction therapy may alter HIF- $1 \alpha$ expression in ESCC. Similar studies on head neck cancer did not show prognostic impact on patients' survival in relation to HIF-1 $\alpha$ expression [1]. For breast cancer, Dales and associates concluded that high HIF-1 $\alpha$ expression correlated with high risk of metastasis and poor survival [5]. Taken together, these results suggest that prognostic significance of expression of HIF- $1 \alpha$ may vary among different cancer types.

Following induction by HIF-1, VEGF is produced in concert with a number of growth factors such as EGF, bFGF, platelet-derived growth factor (PDGF), and transforming growth factor (TGF)- $\beta$ to promote tumor angiogenesis $[16,40]$. These stimulatory factors for VEGF are considered to be produced, in an autocrine and paracrine fashion, from tumor cells, stromal cells, or both by the interaction of tumor cells and host cells [27]. Employing an animal model, VEGF-C and VEGF-D have been shown to induce lymphangiogenesis that is associated with lymph node metastasis [15, 37]. Previous studies on the role of VEGF in tumor angiogenesis and its prognostic significance in different type of human cancers mostly focused on VEGF-C [7, $16,17,31,43]$, leaving limited reports on VEGF-D. Increased VEGF-D expression is associated with lymph node metastasis in colon and prostate $[29,43]$ cancer but not in gastric cancer [35]. In contrast, a few reports demonstrate that expression of VEGF-D is downregulated in tumor tissues compared to that in adjacent normal tissues [11,25], suggesting that VEGF-D may have anti-angiogenic effect relative to VEGF-C. In current study, expression of VEGF-D in ESCC correlated positively with tumor stage and nodal metastasis. Further, we have demonstrated that along with HIF$1 \alpha$, VEGF-D serves as an independent survival predictor for patients undergoing esophagectomy for ESCC. These results were in general agreement with results from a study that compared prognostic significance VEGF-C and VEGF-D expression in patients with colorectal cancer, showing that both of these two factors correlated positively with tumor invasion and nodal metastasis but inversely with overall survival [29]. In contrast, Shida and associates compared expression of VEGF-C and VEGF-D in gastric cancer and demonstrated that only VEGF-C correlated with patients' clinicopathologic variables [35]. These results suggest that prognostic impact of VEGF-D expression may vary in different types of human cancers.

Previous studies rarely investigated relationship between expression of HIF- $1 \alpha$ and VEGF-D in the same series of cancer study. A selective report by Kimura and associates demonstrated that expression HIF- $1 \alpha$ is associated with that of VEGF-C in ESCC and both of these two factors predict patients' survival [16]. In comparison, we have demonstrated that expression of VEGF-D, relative to VEGF-C, was also associated with expression of HIF- $1 \alpha$ in resected ESCC, for which supported by a significant concordance $(69.5 \%)$ between expression of HIF- $1 \alpha$ and VEGF-D. Taken together, the results may imply that different types of VEGF may function synergistically with HIF- $1 \alpha$ in promoting tumor angiogenesis. This speculation needs further investigation on their gene expression and biological functions in relation to tumor angiogenesis using in vitro and/or in vivo models.

The discovery of HIF-1 makes it a potential molecular target for the development of cancer $t$ therapeutics. 
The identification of selective HIF-1inhibitors would not only be useful for the potential therapeutic implications but also for their application as analytic tools to further define the role of HIF in human cancers. Continued efforts have been made in the development of HIF inhibitors, such as synthetic polyamides that inhibit HIF-1 DNA binding [28] and more recently identified small molecule inhibitors (e.g. 103D5R) that selectively blocks HIF-1 protein synthesis [38]. On the other hand, bevacizumab, an anti-VEGF monoclonal antibody, has been proven to be an effective target therapy in a variety of cancers [33]. Our results support a role of HIF-1 and VEGF-D as predictors for poor prognosis in ESCC and provide a reasonable rationale for further investigation in vitro and in vivo with the effects of HIF-1 inhibitors and VEGF-D-targeted therapy for ESCC.

In conclusion, results from this study supported a role of expression of HIF- $1 \alpha$ and VEGF-D as independent survival predictors in resected ESCC and suggested that they may serve as potential therapeutic targets for ESCC. A good correlation between expression of HIF- $1 \alpha$ and VEGF-D suggests that both of these two angiogenic factors are essential for tumor progression or angiogenesis of ESCC.

\section{Acknowledgements}

The authors thank Dr. Mark Ferguson at the University of Chicago Hospitals for his review of this manuscript.

\section{References}

[1] D.M. Aebersold, P. Burri, K.T. Beer, J. Laissue, V. Djonov, R.H. Greiner and G.L. Semenza, Expression of hypoxiainducible factor-1alpha: a novel predictive and prognostic parameter in the radiotherapy of oropharyngeal cancer, Cancer Res 61 (2001), 2911-2916.

[2] T. Amioka, Y. Kitadai, S. Tanaka, K. Haruma, M. Yoshihara, W. Yasui and K. Chayama, Vascular endothelial growth factor$\mathrm{C}$ expression predicts lymph node metastasis of human gastric carcinoma invading the submucosa, Eur J Cancer 38 (2002), 1413-1419.

[3] C. Blancher, J.W. Moore, K.L. Talks, S. Houlbrook and A.L. Harris, Relationship of hypoxia-inducible factor (HIF)-1alpha and HIF-2alpha expression to vascular endothelial growth factor induction and hypoxia survival in human breast cancer cell lines, Cancer Res 60 (2000), 7106-7113.

[4] P. Carmeliet, Y. Dor, J.M. Herbert, D. Fukumura, K. Brusselmans, M. Dewerchin, M. Neeman, F. Bono, R. Abramovitch, P. Maxwell, C.J. Koch, P. Ratcliffe, L. Moons, R.K. Jain, D. Collen and E. Keshert, Role of HIF- $1 \alpha$ in hypoxiamediated apoptosis, cell proliferation and tumor angiogenesis, Nature 394 (1998), 435-439.
[5] J.P. Dales, S. Garcia, S. Meunier-Carpentier, L. AndracMeyer, O. Haddad, M.N. Lavaut, C. Allasia, P. Bonnier and C. Charpin, Overexpression of hypoxia-inducible factor HIF1alpha predicts early relapse in breast cancer: retrospective study in a series of 745 patients, Int J Cancer 116 (2005), 734-739.

[6] J.A. Dibbens, D.L. Miller, A. Damert, W. Risau, M.A. Vadas and G.J. Goodall, Hypoxic regulation of vascular endothelial growth factor mRNA stability requires the cooperation of multiple RNA elements, Mol Biol Cell 10 (1999), 907-919.

[7] L.M. Ellis, W. Liu, F. Fan, N. Reinmuth, R.M. Shaheen, Y.D. Jung and S. Ahmad, Role of angiogenesis inhibitors in cancer treatment, Oncology (Williston Park) 15 (2001), 9-46.

[8] J. Folkman, How is blood vessel growth regulated in normal and neoplastic tissue? G.H.A. Clowes Memorial Award Lecture, Cancer Res 46 (1986), 467-473.

[9] J. Folkman, What is the evidence that tumors are angiogenesis dependent, J Natl Cancer Inst 82 (1990), 4-6.

10] A. Furudoi, S. Tanaka, K. Haruma, Y. Kitadai, M. Yoshihara, K. Chayama and F Shimamoto, Clinical significance of vascular endothelial growth factor $\mathrm{C}$ expression and angiogenesis at the deepest invasive site of advanced colorectal carcinoma, Oncology 62 (2002), 157-166.

[11] M.L. George, M.G. Tutton, F. Janssen, A. Arnaout, A.M. Abulafi, S.A. Eccles and R.I. Swift, VEGF-A, VEGF-C, and VEGF-D in colorectal cancer progression, Neoplasia 3 (2001), 420-427.

[12] F.L. Greene, American Joint Committee on Cancer, American Cancer Society. AJCC Cancer Staging Manual, (6th ed.), New York: Springer, 2002, 93-94.

[13] J.E. Jung, H.G. Lee, I.H. Cho, D.H. Chung, S.H. Yoon, Y.M. Yang, J.W. Lee, S Choi, J.W. Park, S.K. Ye and M.H. Chung, STAT3 is a potential modulator of HIF-1-mediated VEGF expression in human renal carcinoma cells, FASEB J 19 (2005), 1296-1298.

[14] E.L. Kaplan and P. Meier, Nonparametric estimation from incomplete observation, J Am Stat Assoc 53 (1958), 457-481.

[15] T. Karpanen, M. Egeblad, M.J. Karkkainen, H. Kubo, S. YläHerttuala, M. Jäättelä and K. Alitalo, Vascular endothelial growth factor $\mathrm{C}$ promotes tumor lymphangiogenesis and intralymphatic tumor growth, Cancer Res 61 (2001), 1786-1790.

[16] S. Kimura, Y. Kitadai, S. Tanaka, T. Kuwai, J. Hihara, K. Yoshida, T. Toge and K. Chayama, Expression of hypoxiainducible factor (HIF)- $1 \alpha$ is associated with vascular endothelial growth factor expression and tumour angiogenesis in human oesophageal squamous cell carcinoma, Eur J Cancer $\mathbf{4 0}$ (2004), 1904-1912.

[17] Y. Kitadai, K. Haruma, T. Tokutomi, S. Tanaka, K. Sumii, M. Carvalho, M. Kuwabara, K. Yoshida, T. Hirai, G. Kajiyama and E. Tahara, Significance of vessel count and vascular endothelial growth factor in human esophageal carcinomas, Clin Cancer Res 4 (1998), 2195-2200.

[18] A.L. Kung, S. Wang, J.M. Klco, W.G. Kaelin and D.M. Livingston, Suppression of tumor growth through disruption of hypoxia inducible transcription, Nat Med 6 (2000), 13351340.

[19] P.A. Kyzas, D. Stefanou, A. Batistatou and N.J. Agnantis, Hypoxia-induced tumor angiogenic pathway in head and neck cancer: an in vivo study, Cancer Lett 225 (2005), 297-304.

[20] P.A. Kyzas, D. Stefanou and N.J. Agnantis, Immunohistochemical expression of vascular endothelial growth factor correlates with positive surgical margins and recurrence in $\mathrm{T} 1$ and T2 squamous cell carcinoma (SCC) of the lower lip, Oral Oncol 40 (2004), 941-947. 
[21] C. Leo, A.J. Giaccia and N.C. Denko, The hypoxic tumor microenvironment and gene expression, Semin Radiat Oncol 14 (2004), 207-214.

[22] N. Matsutani, W. Yasui and K. Chayama, Clinicopathological significance of vascular endothelial growth factor (VEGF)-C in human esophageal squamous cell carcinoma, Int $J$ Cancer 93 (2001), 662-666.

[23] G. Melillo, Inhibiting hypoxia-inducible factor 1 for cancer therapy, Mol Cancer Res 4 (2006), 601-605.

[24] C. Michiels, E. Minet, D. Mottet and M. Raes, Regulation of gene expression by oxygen: NF-kappaB and HIF-1, two extremes, Free Radic Biol Med 33 (2002), 1231-1242.

[25] T. Niki, S. Iba, M. Tokunou, T. Yamada, Y. Matsuno and S. Hirohashi, Expression of vascular endothelial growth factors A, B, C, and D and their relationships to lymph node status in lung adenocarcinoma, Clin Cancer Res 6 (2000), 2431-2439.

[26] P. O-charoenrat, P. Rhys-Evans and S.A. Eccles, Expression of vascular endothelial growth factor family members in head and neck squamous cell carcinoma correlates with lymph node metastasis, Cancer 92 (2001), 556-568.

[27] Y. Ogata, H. Fujita, H. Yamana, S. Sueyoshi and K. Shirouzu, Expression of vascular endothelial growth factor as a prognostic factor in node-positive squamous cell carcinoma in the thoracic esophagus: long-term follow-up study, World J Surg 27 (2003), 584-589.

[28] B.Z. Olenyuk, G.J. Zhang, J.M. Klco, N.G. Nickols, W.G. Jr. Kaelin and P.B. Dervan, Inhibition of vascular endothelial growth factor with a sequence-specific hypoxia response element antagonist, Proc Natl Acad Sci USA 101 (2004), 1676816773.

[29] S. Onogawa, Y. Kitadai, S. Tanaka, T. Kuwai, S. Kimura and K. Chayama, Expression of VEGF-C and VEGF-D at the invasive edge correlates with lymph node metastasis and prognosis of patients with colorectal carcinoma, Cancer Sci 95 (2004), 32-39.

[30] C.W. Pugh and P.J. Ratcliffe, Regulation of angiogenesis by hypoxia: role of the HIF system, Nat Med 9 (2003), 677-684.

[31] N. Reinmuth, A.A. Parikh, S.A. Ahmad, W. Liu, O. Stoeltzing, F. Fan, A. Takeda, M. Akagi and L.M. Ellis, Biology of angiogenesis in tumors of the gastrointestinal tract, Microsci Res Tech 60 (2003), 199-207.

[32] H.E. Ryan, M. Poloni, W. McNulty, D. Elson, M. Gassmann, J.M. Arbeit and R.S. Johnson, Hypoxia-inducible factor- $1 \alpha$ is a positive factor in solid tumor growth, Cancer Res 60 (2000), 4010-4015.

[33] A. Sandler, Bevacizumab in non small cell lung cancer, Clin Cancer Res 13 (2007), s4613-s4616.

[34] G.L. Semenza, Signal transduction to hypoxia-inducible factor 1, Biochem Pharmacol 64 (2002), 993-998.
[35] A. Shida, S. Fujioka, K. Kobayashi, Y. Ishibashi, H. Nimura, N. Mitsumori and K. Yanaga, Expression of vascular endothelial growth factor (VEGF)-C and -D in gastric carcinoma, Int J Clin Oncol 11 (2006), 38-43.

[36] B.D. Smith, G.L. Smith, D. Carter, C.T. Sasaki and B.G. Hafty, Prognostic significance of vascular endothelial growth factor protein levels in oral and oropharyngeal squamous cell carcinoma, J Clin Oncol 18 (2000), 2046-2052.

[37] S.A. Stacker, C. Caesar, M.E. Baldwin, G.E. Thornton, R.A. Williams, R. Prevo, D.G. Jackson, S. Nishikawa, H. Kubo and M.G. Achen, VEGF-D promotes the metastatic spread of tumor cells via the lymphatics, Nat Med 7 (2001), 186-191.

[38] C. Tan, R.G. de Noronha, A.J. Roecker, B. Pyrzynska, F. Khwaja, Z. Zhang, H. Zhang, Q. Teng, A.C. Nicholson, P. Giannakakou, W. Zhou, J.J. Olson, M.M. Pereira, K.C. Nicolaou and E.G. Van Meir, Identification of a novel small-molecule inhibitor of the hypoxia-inducible factor 1 pathway, Cancer Res 65 (2005), 605-612.

[39] The Lifetest Procedure, in: SAS Technical Report: P-179, Additional SAS/STAT Procedures, Release 6.03. Cary NC: SAS Institute, 1988, 49-90.

[40] J.C. Tsai, C.K. Goldman and G.Y. Gillespie, Vascular endothelial growth factor in human glioma cell lines: induced secretion by EGF, PDGF-BB, and bFGF, J Neurosurg 82 (1995), 864-873.

[41] T. Veikkola and K. Alitalo, VEGFs, receptors and angiogenesis, Semin CancerBiol 9 (1999), 211-220.

[42] G.L. Wang, B.H. Jiang, E.A. Rue and G.L. Semenza, Hypoxiainducible factor 1 is a basic helix-loop-helix-PAS heterodimer regulated by cellular O2 tension, Proc Natl Acad Sci USA 92 (1995), 5510-5514.

[43] Y. Zeng, K. Opeskin, M.E. Baldwin, L.G. Horvath, M.G. Achen, S.A. Stacker, R.L. Sutherland and E.D. Williams, Expression of vascular endothelial growth factor receptor-3 by lymphatic endothelial cells is associated with lymph node metastasis in prostate cancer, Clin Cancer Res 10 (2004), 5137-5144.

[44] Q. Zhang, Z.F. Zhang, J.Y. Rao, J.D. Sato, J. Brown, D.V. Messadi and A.D. Le, Treatment with siRNA and antisense oligonucleotides targeted to HIF-1alpha induced apoptosis in human tongue squamous cell carcinomas, Int J Cancer 111 (2004), 849-857.

[45] H. Zhong, A.M. De Marzo, E. Laughner, M. Lim, D.A. Hilton, D. Zagzag, P. Buechler, W.B. Isaacs, G.L. Semenza and J.W. Simons, Overexpression of hypoxia-inducible factor $1 \alpha$ in common human cancers and their metastases, Cancer Res 59 (1999), 5830-5835. 


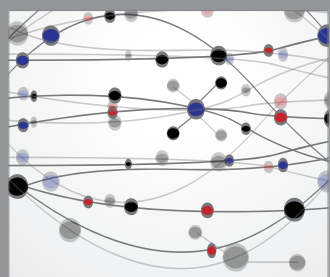

The Scientific World Journal
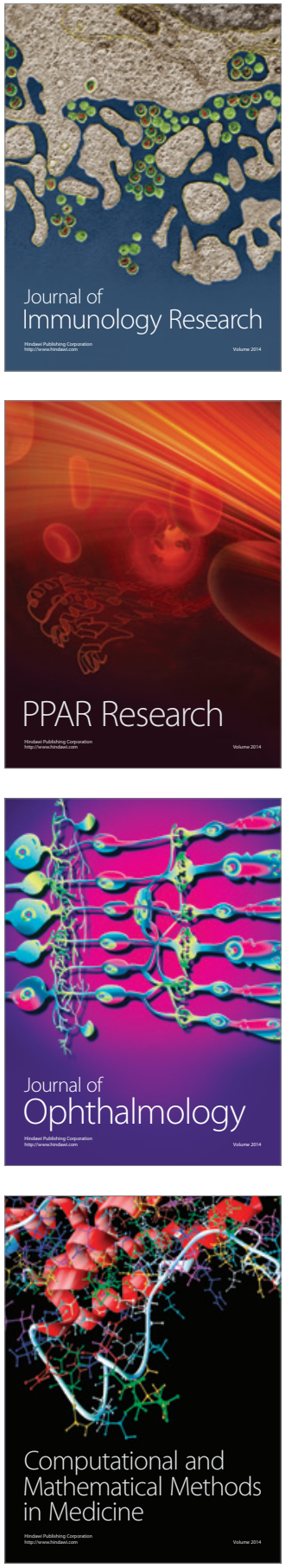

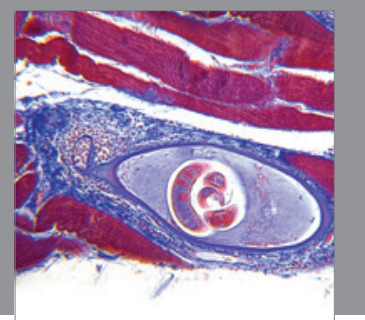

Gastroenterology

Research and Practice
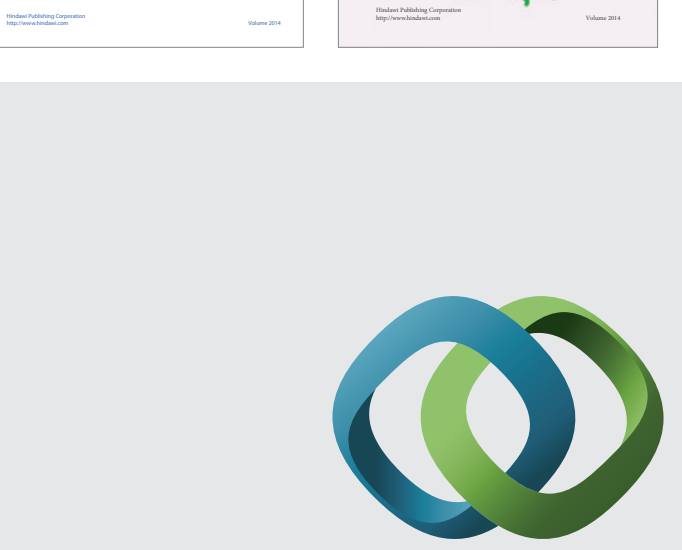

\section{Hindawi}

Submit your manuscripts at

http://www.hindawi.com
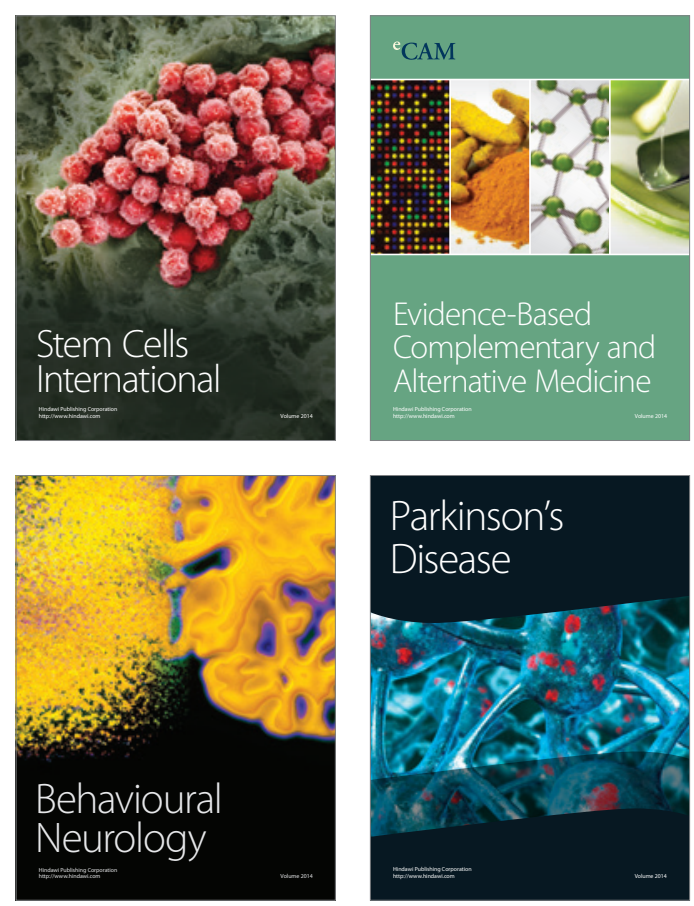

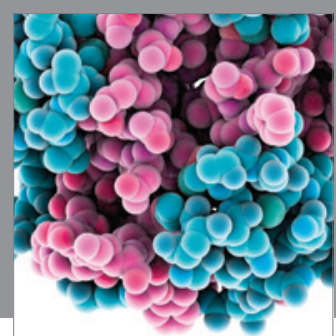

Journal of
Diabetes Research

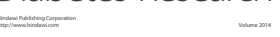

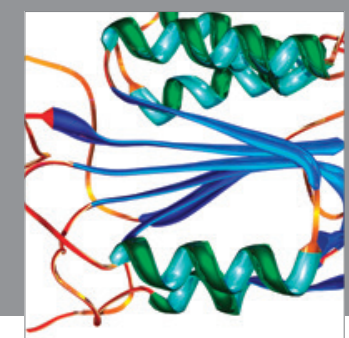

Disease Markers
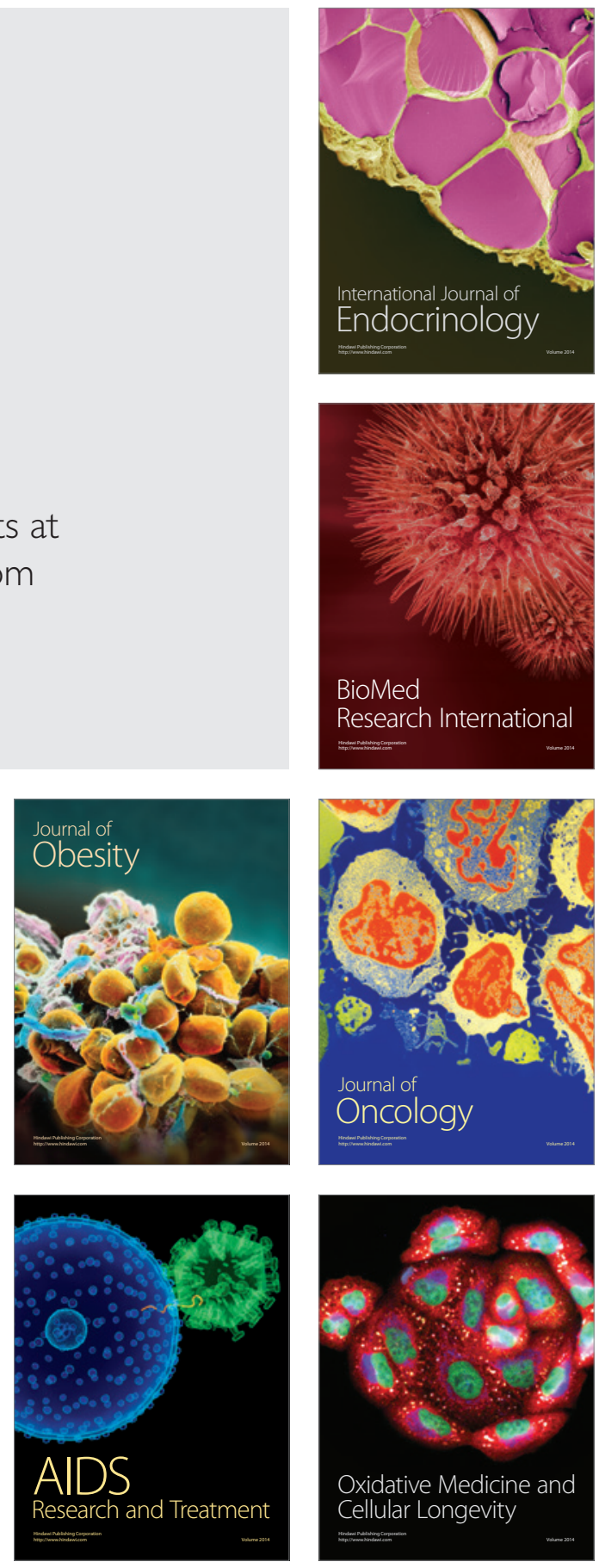